\title{
Determination of Glyphosate and Glufosinate in Human Serum by MonoSpin TiO Extraction and Liquid Chromatography-Tandem Mass Spectrometry
}

\author{
Takeshi Saito $^{1 *}$, Akira Namera ${ }^{2}$, Tomoatsu Tsuji ${ }^{1}$, Wataru Noguchi ${ }^{3}$ and Sadaki Inokuchi ${ }^{1}$ \\ 'Department of Emergency and Critical Care Medicine, Tokai University School of Medicine, Isehara, Kanagawa 259-1143, Japan \\ Department of Forensic Medicine, Graduate School of Biomedical and Health Sciences, Hiroshima University, \\ Kasumi 1-2-3, Minami-ku, Hiroshima 734-8553, Japan \\ ${ }^{3}$ Department of Emergency, Kagoshima City Hospital, Uearata, Kagoshima, Kagoshima 890-8760, Japan
}

Received: 03 July 2018; accepted: 23 August 2018

\begin{abstract}
We developed and validated an assay for determination of glyphosate (GLYP) and glufosinate (GLUF) in human serum. Serum samples were extracted by using a MonoSpin ${ }^{\circledR} \mathrm{TiO}$ column and analyzed by liquid chromatography-tandem mass spectrometry (LC-MS/MS). MonoSpin ${ }^{\circledR}$ TiO tends to specifically bind to phosphate groups. The assay was linear over a concentration range of $1-250 \mu \mathrm{g} / \mathrm{mL}$. The recoveries for the 2 compounds were $1.6 \%-2.3 \%$. The intra- and inter-day variations were $<15 \%$. Precision and accuracy were $5.6 \%-12.7 \%$ and $97.0 \%-103.9 \%$, respectively. The validated method was applied to quantify the GLYP and GLUF content in the serum of GLYP and GLUF-poisoned patients. In conclusion, the method was successfully applied for accurate determination of GLYP and GLUF in serum obtained from patients with GLYP and GLUF poisoning.
\end{abstract}

Keywords: glyphosate, glufosinate, MonoSpin TiO column, serum

\section{Introduction}

Glyphosate ( $N$-[phosphonomethyl]glycine) (GLYP) and glufosinate (GLUF) (DL-homoalanin-4-yl-[methyl]phosphinate ammonium salt) are phosphonic and amino acid groupcontaining chemicals that constitute an important category of pesticides and are extensively used as herbicides in many countries, including Japan. GLYP and GLUF-surfactant herbicides are the most frequently used nonselective herbicide. However, numerous cases of accidental and suicidal poisoning due to the ingestion of these herbicides in attempted suicides have been reported [1-6].

Although GLYP and GLUF herbicides poisoning was probably caused by surfactant [1], these surfactants are not disclosed by the manufacturers. Serum GLYP and GLUF concentrations were used for the alternative method of assessing poisoning states. Moreover, GLYP and GLUF products contained a surfactant - an isopropylamine salt or partial ammonium salt-before 2006. However, a part of GLYP products has been changed to contain $48 \%$ GLYP potassium salt in Japan since 2006. Thereafter, the incidence of mortality cases with hyperkalemia due to GLYP herbicide ingestion gradually increased. Although GLYP herbicide poisoning causes hyperkalemia, GLUF herbicide poisoning is still caused by a surfactant in the formulation. Although GLYP herbicide ingestion may be suspected by the presence of hyperkalemia, the early diagnosis and appropriate treatment of GLUF and GLYP may be lifesaving.

Recently, we developed a simple derivatization method for gas chromatography (GC)-mass spectrometry (MS) analyses of GLYP and GLUF [7-9], because the previously reported sample preparation method, especially the derivatization procedure, is time consuming [10-16]. However, GLYP and

\footnotetext{
*Author for correspondence: saito@is.icc.u-tokai.ac.jp; tel: +81-463-93-1121;
} fax: +81-463-95-5337.
GLUF were frequently not detected after derivatization, especially after acylated derivatized sample analyses.

Recently, Yoshioka et al. reported an analytical method using liquid chromatography (LC)-MS/MS for bialaphos (BIA), GLYP, and GLUF without derivatization [17]. Although their external standardization for extraction is usually more convenient and less expensive, an internal standard (IS) can be a useful tool for negative analytical results. Therefore, we developed rapid extraction method using an IS for identification of GLYP and GLUF. This method used a MonoSpin ${ }^{\circledR}$ $\mathrm{TiO}$ column for extraction and LC-MS/MS for analysis.

\section{Materials and Methods}

GLUF ammonium and GLYP were obtained from Wako (Osaka, Japan). DL-2-amino-3-phosphonopropionic acid was purchased from Sigma (St. Louis, MO, USA). MonoSpin ${ }^{\circledR}$ TiO cartridges (5010-21706) were used for extraction from serum samples (GL Sciences, Tokyo, Japan). Acetonitrile for LC-MS and formic acid were purchased from Sigma-Aldrich (St. Louis, MO, USA) and Nacalai Tesque (Kyoto, Japan), respectively. All other chemicals and reagents were of analytical grade (Wako, Japan). Serum samples for the validation study were collected from volunteers from hospital staff who were not using any medication. Frozen serum samples $\left(-30{ }^{\circ} \mathrm{C}\right)$ were stored at room temperature until complete thawing and vortex-mixed $1 \mathrm{~min}$ before use.

\section{Calibration Curve and Quality Control Samples}

GLYP and GLUF $(10 \mathrm{mg} / \mathrm{mL})$ were prepared in $10 \%$ methanol. These solutions were further diluted with $10 \%$ methanol to concentrations of $1 \mathrm{mg} / \mathrm{mL}, 100 \mu \mathrm{g} / \mathrm{mL}, 10 \mu \mathrm{g} / \mathrm{mL}$, and $1 \mu \mathrm{g} / \mathrm{mL}$ and stored for a maximum of 3 months at $4{ }^{\circ} \mathrm{C}$. These solutions were used as calibrators. A stock solution of DL-2-amino-3-phosphonopropionic acid (1 mg/mL) was prepared in $10 \%$ methanol and used as an IS stock solution. The

This is an open-access article distributed under the terms of the Creative Commons Attribution-NonCommercial 4.0 International License (https://creativecommons.org/licenses/by-nc/4.0/), which permits unrestricted use, distribution, and reproduction in any medium for non-commercial purposes, provided the original author and source are credited, a link to the CC License is provided, and changes - if any - are indicated. 
IS stock solution was further diluted with $10 \%$ methanol to a concentration of $100 \mu \mathrm{g} / \mathrm{mL}$. Blank serum samples (final volume of $100 \mu \mathrm{L})$ were spiked with $10 \mu \mathrm{L}$ of calibrator $(10 \mu \mathrm{g} / \mathrm{mL})$, $5 \mu \mathrm{L}$ of calibrator $(100 \mu \mathrm{g} / \mathrm{mL}), 2.5 \mu \mathrm{L}$ of calibrator $(1 \mathrm{mg} / \mathrm{mL})$, $5 \mu \mathrm{L}$ of calibrator $(1 \mathrm{mg} / \mathrm{mL}), 10 \mu \mathrm{L}$ of calibrator $(1 \mathrm{mg} / \mathrm{mL})$, and $2.5 \mu \mathrm{L}$ of calibrator $(10 \mathrm{mg} / \mathrm{mL})$ resulting in calibration samples containing $0.1(1 \mu \mathrm{g} / \mathrm{mL}), 0.5(5 \mu \mathrm{g} / \mathrm{mL}), 2.5(25 \mu \mathrm{g} / \mathrm{mL})$, $5(50 \mu \mathrm{g} / \mathrm{mL}), 10(100 \mu \mathrm{g} / \mathrm{mL})$, and $25(250 \mu \mathrm{g} / \mathrm{mL}) \mu \mathrm{g}$ of each compound, i.e., GLYP and GLUF.

Each quality control (QC) solution was prepared in the same manner as mentioned above. QC samples were prepared by using blank serum samples (final volume of $100 \mu \mathrm{L}$ ) containing 0.1 (limit of quantitation [LOQ]: $10 \mu \mathrm{L}$ of $10 \mu \mathrm{g} / \mathrm{mL}$; $1 \mu \mathrm{g} / \mathrm{mL}$ ), 0.25 (low QC level: $2.5 \mu \mathrm{L}$ of $100 \mu \mathrm{g} / \mathrm{mL} ; 2.5 \mu \mathrm{g} / \mathrm{mL}$ ), 4 (medium QC level: $4 \mu \mathrm{L}$ of $1 \mathrm{mg} / \mathrm{mL} ; 40 \mu \mathrm{g} / \mathrm{mL}$ ), and 20 (high QC level: $2 \mu \mathrm{L}$ of $10 \mathrm{mg} / \mathrm{mL} ; 200 \mu \mathrm{g} / \mathrm{mL}$ ) $\mu \mathrm{g}$ of each compound. A total of $24 \mathrm{QC}$ samples were prepared for a batch.

\section{Extraction Procedure}

Sample Preparation and Extraction. A MonoSpin ${ }^{\circledR} \mathrm{TiO}$ column was used for extraction from serum sample. The human serum standards for calibration were prepared by spiking the standard working solution and IS solution $(20 \mu \mathrm{L}$ of $100 \mu \mathrm{g} / \mathrm{mL} ; 2 \mu \mathrm{g}$ ) into a pool of blank human serum (final volume of $100 \mu \mathrm{L}$ ). QC samples at 4 concentrations were prepared by spiking the appropriate standard working solutions and IS solution into blank human serum $(100 \mu \mathrm{L})$.

A $400-\mu \mathrm{L}$ aliquot of $0.1 \%$ acetic acid was added to $100 \mu \mathrm{L}$ of the serum sample and mixed on a vortexer for $15 \mathrm{~s}$.

The MonoSpin ${ }^{\circledR} \mathrm{TiO}$ column was conditioned with $200 \mu \mathrm{L}$ of methanol at $3000 \mathrm{rpm}$ for $1 \mathrm{~min}$ followed by $200 \mu \mathrm{L}$ of $0.1 \%$ acetic acid at $3000 \mathrm{rpm}$ for $1 \mathrm{~min}$. The samples were applied to the conditioned MonoSpin ${ }^{\circledR} \mathrm{TiO}$ column. The column was centrifuged for $1 \mathrm{~min}$ at $3000 \mathrm{rpm}$. The column was washed with $200 \mu \mathrm{L} \mathrm{H} \mathrm{H}_{2} \mathrm{O}$ at $3000 \mathrm{rpm}$ for $1 \mathrm{~min}$. Finally, the samples were eluted with $200 \mu \mathrm{L}$ acetonitrile at $3000 \mathrm{rpm}$ for $1 \mathrm{~min}$ and $200 \mu \mathrm{L}$ acetonitrile-ammonia solution (9:1) at $3000 \mathrm{rpm}$ for $1 \mathrm{~min}$ in a new tube. The collected samples were dried under stream nitrogen at $45{ }^{\circ} \mathrm{C}$. The resulting samples were dissolved in $100 \mu \mathrm{L}$ acetonitrile- $0.1 \%$ formic acid (80:20) and injected into the LC-MS/MS system.

The calibration curves, QC, and clinical serum samples were extracted by using the same procedure.

\section{LC-MS/MS Analysis}

LC-MS/MS Conditions. Chromatographic separation was performed by using an Obelisc N $5-\mu \mathrm{m}(2.1 \mathrm{~mm} \times 150 \mathrm{~mm})$ column (SIELC Technologies Inc., Wheeling, IL, USA) at $40{ }^{\circ} \mathrm{C}$ in an Agilent 1200 LC system (Agilent, Santa Clara, CA, USA). Separation was performed with isocratic elution of $0.1 \%$ formic acid-acetonitrile $(80: 20, v / v)$ at a flow rate of $0.4 \mathrm{~mL} / \mathrm{min}$. The total data acquisition time was $7.0 \mathrm{~min} / \mathrm{sample}$. The injection volume was $10 \mu \mathrm{L}$.

Electrospray ionization-tandem mass spectrometry (ESIMS/MS) detection was achieved on an Agilent 6410 triple quadrupole tandem mass spectrometer. The positive ionization mode was used, and the ions were monitored in the multiple reaction monitoring (MRM) mode. ESI source parameters were as follows: high-purity drying gas $\left(\mathrm{N}_{2}\right)$ flow rate, $6 \mathrm{~L} / \mathrm{min}$; temperature, $300{ }^{\circ} \mathrm{C}$; capillary voltage, $4000 \mathrm{~V}$; and nebulizer, 15 psi.

Limit of Detection (LOD) and Limit of Quantitation (LOQ). LOD was defined on the basis of the standard deviation (SD) of the response and the slope (S) of calibration curves at levels approximating the LOD according to the following formula: $\mathrm{LOD}=3.3(\mathrm{SD} / \mathrm{S})$. Similarly, LOQ was defined on the basis of the SD of the response and $\mathrm{S}$ of calibration curves at levels approximating the LOQ according to the following formula: $\mathrm{LOQ}=10(\mathrm{SD} / \mathrm{S})[18]$.

Precision and Accuracy. The intra- and inter-day percent relative standard deviations (\%RSDs) were obtained by using blank serum samples spiked with 4 QC samples. For the intra- and inter-day assays, 6 replicates of each concentration were prepared and analyzed. Four QC samples were prepared every time and analyzed for 3 consecutive days. The accuracy was measured as the percentage deviation from the nominal concentration. The criteria for the acceptability of data included accuracy within $\pm 15 \%$ of deviation from the nominal values and a precision within $\pm 15 \%$ of the RSD except for the lowest LOQ, which could not exceed $20 \%$ of RSD [19].

Extraction Recovery and Matrix Effects. We evaluated the extraction recovery of GLYP and GLUF from the blank serum by analyzing 6 replicates of 2 sets of QC samples. The first set A consisted of $100 \mu \mathrm{L}$ of blank serum added to the 4 QC solutions and IS with $400 \mu \mathrm{L}$ of $0.1 \%$ acetic acid and then extracted by using a MonoSpin ${ }^{\circledR} \mathrm{TiO}$ column. The second set B consisted of $100 \mu \mathrm{L}$ of blank serum added to $400 \mu \mathrm{L}$ of $0.1 \%$ acetic acid, and the 4 QC solutions and IS were added after MonoSpin ${ }^{\circledR}$ TiO extraction of the sample. Then, the samples were prepared in the same manner and analyzed by the LC-MS/MS system. A comparison of the mean GLUF and GLYP integrated peak areas, (set A/set B) $\times$ $100 \%$, provided the extraction recovery of GLUF and GLYP expressed in percentage.

The 4 QC solutions and IS were dissolved in acetonitrile just before LC-MS/MS analysis $(\mathrm{C})$. The ratio $(\mathrm{B} / \mathrm{C} \times 100)$ defines the matrix effects. The reproducibility of the extraction procedure was determined as \%RSD.

\section{Patient's Samples}

Case 1. A 55-year-old Japanese female attempted to commit suicide by ingesting an unknown volume of Basta ${ }^{\circledR}$ (18.5\% glufosinate). She was admitted to the hospital by her husband and then transferred to a city hospital for further examination on the same day. On admission to City Hospital, she had a Glasgow Coma Scale of 1-1-4 (Japan Coma Scale 300 ), a systolic blood pressure of $170 \mathrm{mmHg}$, and a heart rate of 132 beats/min. She was transported to the intensive care unit (ICU) and intubated. However, she had marked blood pressure reduction and tachyrhythmia. Over a 7-day period, she was extubated in the ICU.

Case 2. A 65-year-old Japanese male attempted suicide by ingesting approximately $250 \mathrm{~mL}$ of Roundup ${ }^{\circledR}(48 \%$ glyphosate-potassium salt). Thereafter, he was in agony because of vomiting and diarrhea and was transferred to our emergency department, approximately $2 \mathrm{~h}$ after ingestion. On admission, he received cardiopulmonary resuscitation with intubation. However, he died despite intensive care 7 months later.

\section{Results and Discussion}

The precursor and product ions for each compound are presented in Table 1 . These conditions were slightly different from those reported elsewhere [17]. The typical MRM chromatograms of the blank serum and spiked low QC and IS are shown in Figure 1. GLYP, GLUF, and IS were not detected in the blank serum. These chromatograms revealed that there was no interfering peak derived from the endogenous components at the elution times of GLYP, GLUF, and the IS. The peaks corresponding to GLUF, IS, and GLYP were clearly observed at 3.35, 4.45, and $5.18 \mathrm{~min}$, respectively (Figures 1-3). 
Table 1. Precursor ions, product ions and their respective collision energy for each compound

\begin{tabular}{lccc}
\hline & $\begin{array}{c}\text { Precursor ion } \\
(\mathrm{m} / \mathrm{z})\end{array}$ & $\begin{array}{c}\text { Product ion } \\
(\mathrm{m} / \mathrm{z})\end{array}$ & $\begin{array}{c}\text { Collision } \\
\text { energy (V) }\end{array}$ \\
\hline Glyphosate & 170.0 & $88.1^{a}$ & 5 \\
& & $60.1^{b}$ & 17 \\
Glufosinate & 182.1 & $56.1^{a}$ & 25 \\
DL-2-amino- & & $136.0^{b}$ & 13 \\
3-phosphonopropionic acid (IS) & 170.0 & $124.0^{a}$ & 13 \\
$\quad{ }^{a}$ Quantitative ion. & & $106.0^{b}$ & 25 \\
${ }^{b}$ Qualitative ion. & & \\
\hline
\end{tabular}

The LOD of GLYP and GLUF was $0.5 \mu \mathrm{g} / \mathrm{mL}$ for each. Based on the above criterion, the LOQ of GLYP and GLUF was determined to be $1 \mu \mathrm{g} / \mathrm{mL}$ for each, when a $100-\mu \mathrm{L}$ serum sample was used.

The validation data for the analytical method in terms of accuracy and precision are summarized in Table 2. Data from the QC samples that were run in sextuplicate at each concentration on each of these 3 days are also presented in Table 2.

The calibration curves of GLYP and GLUF were linear over the concentration range from 1 to $250 \mu \mathrm{g} / \mathrm{mL}$ for both compounds. A linear regression analysis of the plot of the peakarea ratios $(y)$ of the target to the IS versus the target
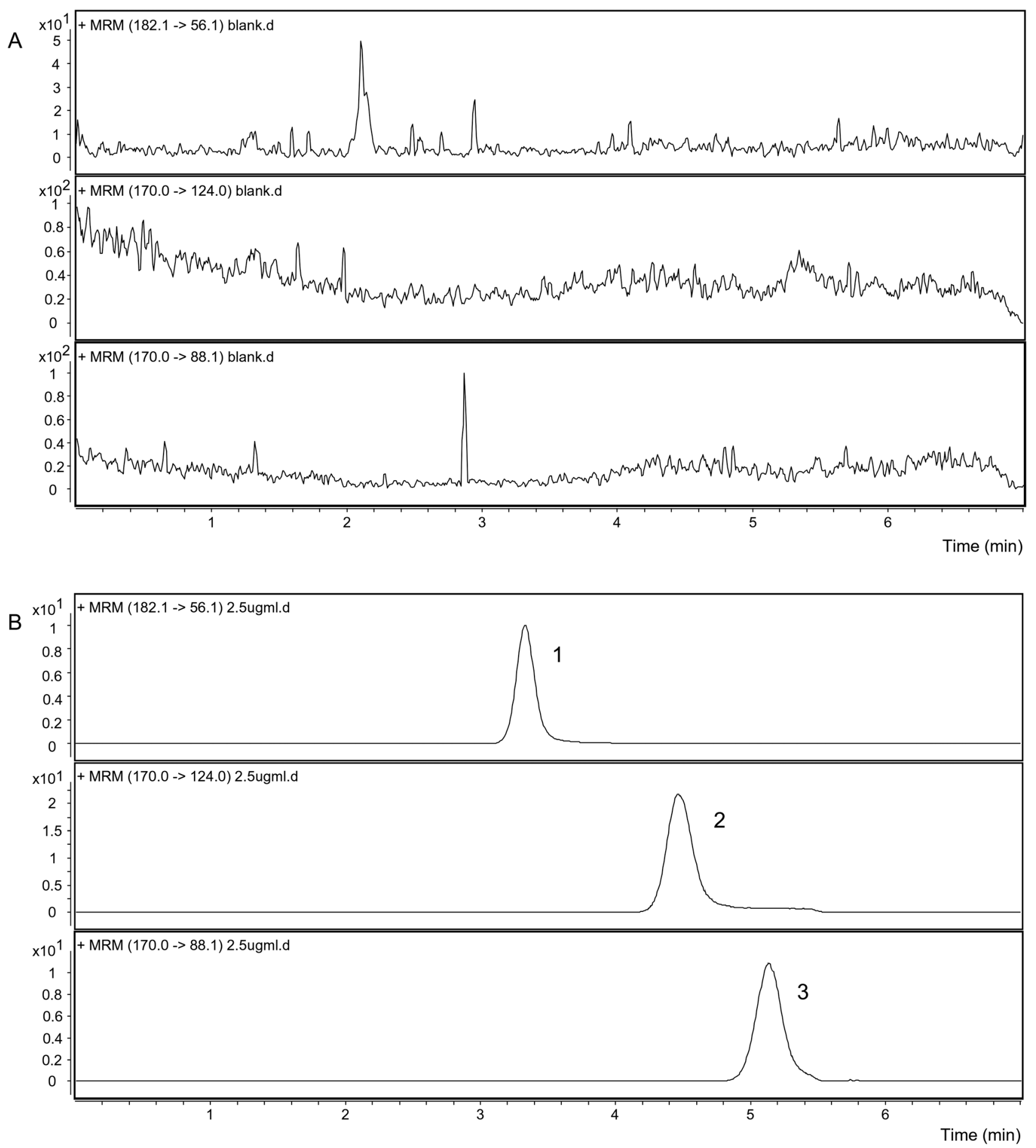

Figure 1. Liquid chromatography-tandem mass spectrometry chromatograms obtained by MonoSpin ${ }^{\circledR} \mathrm{TiO}$ column extraction of (A) blank human serum, (B) blank human serum with low QC level (glufosinate [GLUF], $2.5 \mu \mathrm{g} / \mathrm{ml}$; glyphosate [GLYP], $2.5 \mu \mathrm{g} / \mathrm{ml}$ ), and the internal standard (IS). 1: GLUF, 2: IS, and 3: GLYP 

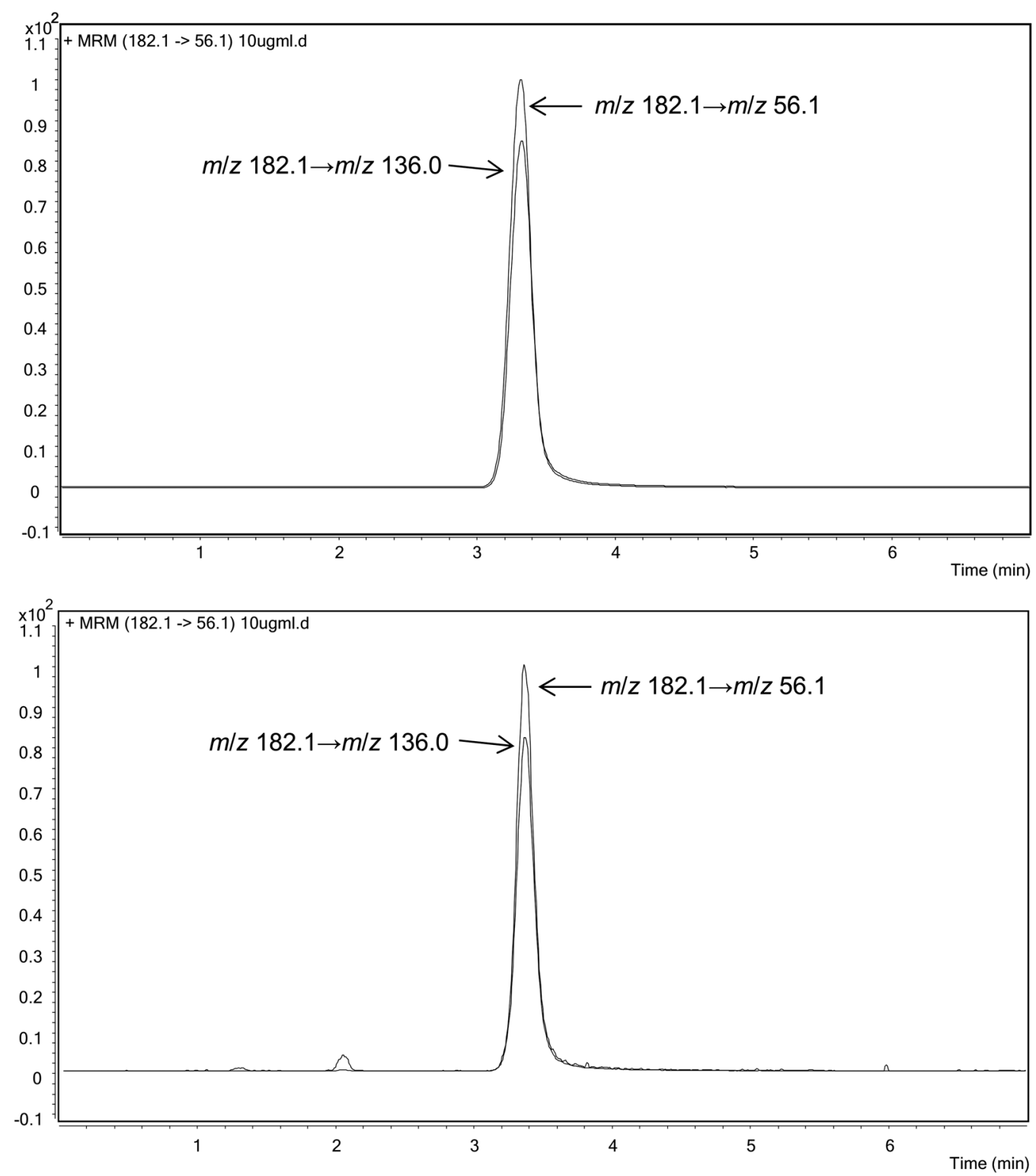

Figure 2. MRM chromatograms of standard of GLUF (upper). MRM chromatograms obtained by MonoSpin ${ }^{\circledR}$ TiO column extraction of blank human serum with GLUF $(10 \mu \mathrm{g} / \mathrm{mL})$ (bottom)

concentrations was performed. The regression equations for GLYP and GLUF were $y=0.0529 x+0.1102$ and $y=0.1495 x$ +0.2370 , respectively. The SDs of the slope and the intercept in GLYP regression equation were 0.0060 and 0.0370 , respectively. Similarly, the SDs of the slope and the intercept in GLUF regression equation were 0.0142 and 0.0423 , respectively. The average coefficient of determination $\left(r^{2}\right)$ was always $>0.998$. The experimental peak-area ratios were interpolated on the calibration curve, and the concentrations were back-calculated. The mean back-calculated concentrations approached the spiked concentrations, as shown by an RSD of $<15 \%$.

The LOD using our previous method for GLYP and GLUF was slightly better than that using the presented method [7-9, $12,13]$; previously, GLUF was analyzed in human serum and had an LOD of $0.1 \mu \mathrm{g} / \mathrm{mL}[7-9,12,13]$. These values appeared to be in the same order of magnitude as the values estimated by the methodology presented herein.

The GLUF and GLYP concentrations in the serum after a few hours of GLUF and GLYP ingestion were $>24 \mu \mathrm{g} / \mathrm{mL}$ and more than a few thousand $\mu \mathrm{g} / \mathrm{mL}$, respectively $[4,8,9]$. Therefore, the linearity range included the LOD and LOQ values for GLYP and GLUF in this method. Although the
LC-MS/MS method is usually superior to the GC-MS method, the linearity range for GLYP and GLUF obtained by using our presented method was narrower than that obtained by using the previously reported GC-MS method [7-9, 12, 13]. This narrow linearity range can probably be explained by the extraction recovery method using MonoSpin ${ }^{\circledR}$ TiO. However, Yoshioka et al. reported [17] that GLYP and GLUF concentration in serum was analyzed using LC-MS/MS, and the higher linearity ranges for both compounds are up to $20 \mu \mathrm{g} / \mathrm{mL}$ according to their paper. The LODs for GLYP and GLUF in their method were 0.03 and $0.07 \mu \mathrm{g} / \mathrm{mL}$, respectively. Similarly, the LOQs for GLYP and GLUF were 0.09 and $0.1 \mu \mathrm{g} / \mathrm{mL}$, respectively. This higher linearity range was 10 times lesser than that in our method. Although our method is suitable for the analysis of higher blood concentrations of GLYP and GLUF in acute intoxication, their method is suitable for the analysis of even trace levels after intensive care.

Assay Precision and Accuracy. The \%RSD of the intraday assay $(n=6)$ for the serum GLYP and GLUF concentration was $<12.7 \%$, and good inter-day $(n=6)$ RSD values $(<12.1 \%)$ were also obtained, as shown in Table 2 .

Extraction Recovery. Table 2 presents the results of the extraction recovery for the 4 QC levels. The overall 

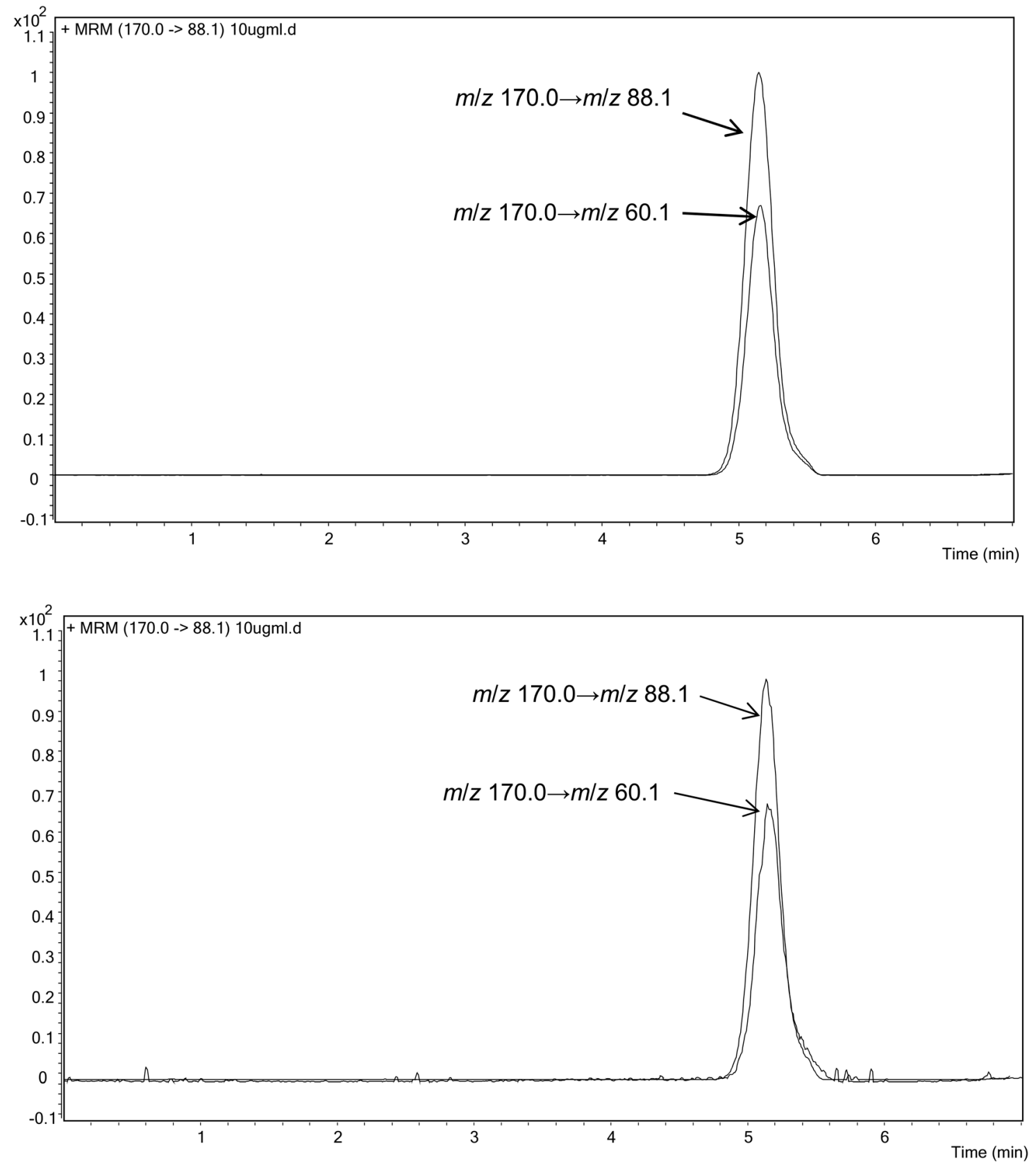

Figure 3. MRM chromatograms of standard of GLYP (upper). MRM chromatograms obtained by MonoSpin ${ }^{\circledR}$ TiO column extraction of blank human serum with GLYP $(10 \mu \mathrm{g} / \mathrm{mL})$ (bottom)

Table 2. Method performance: recovery, accuracy, precision, and matrix effect

\begin{tabular}{cccrrrr}
\hline \multirow{6}{*}{$\begin{array}{c}\text { QC conc. } \\
(\mathrm{ng} / \mathrm{mL})\end{array}$} & $\begin{array}{c}\text { Recovery } \\
(\%)\end{array}$ & $\begin{array}{r}\text { Accuracy } \\
(\%)\end{array}$ & $\begin{array}{r}\text { Intra-day } \\
\text { Precision } \\
(\%)\end{array}$ & $\begin{array}{r}\text { Inter-day } \\
\text { Precision } \\
(\%)\end{array}$ & $\begin{array}{r}\text { Matrix } \\
\text { effect }\end{array}$ \\
\hline \multirow{6}{*}{ Glufosinate } & 1 & 1.6 & 97.0 & 11.7 & 10.6 & 103.9 \\
& 2.5 & 1.7 & 100.3 & 6.0 & 5.1 & 105.4 \\
& 40 & 1.9 & 101.2 & 9.7 & 8.8 & 104.7 \\
& 200 & 2.0 & 103.9 & 8.1 & 7.4 & 104.7 \\
Glyphosate & 1 & 2.3 & 97.3 & 12.7 & 9.9 & 98.6 \\
& 2.5 & 2.3 & 100.9 & 6.0 & 5.5 & 99.2 \\
& 40 & 2.1 & 103.7 & 9.6 & 8.4 & 101.2 \\
& 200 & 2.2 & 99.4 & 10.0 & 7.4 & 100.9 \\
\hline
\end{tabular}

recoveries in the serum samples ranged from $1.6 \%$ to $2.3 \%$ for GLYP and GLUF at the 4 QC levels. The overall extraction recoveries of GLYP and GLUF from the serum were very low.

Although TiO tends to bind to phosphate groups, the MonoSpin disk is thin. Therefore, the amount of phosphate groups held by TiO should be small, but this binding leads to low recovery. However, ion suppression was not detected and was approximately $100 \%$ in all QCs. We have previously reported that the greatest loss of GLUF and GLYP during sample processing occurred during deproteinizing [7]. Moreover, ion suppression was approximately $50 \%-60 \%$. Although the recovery from MonoSpin $\mathrm{TiO}$ was very low, ion suppression did not occur because the selectivity for phosphorous is high.

Yoshioka et al. reported [17] that $500 \mu \mathrm{L}$ of serum was ultrafiltered, and $300 \mu \mathrm{L}$ of passage was used for further preparation. Their validation samples for recovery of GLYP and GLUF were also prepared in $500 \mu \mathrm{L}$ of serum at $0.2 \mu \mathrm{g} / \mathrm{mL}$ and $5 \mu \mathrm{g} / \mathrm{mL}$ after ultrafiltration performed by using the same procedure. Although the recovery ranged between $94.5 \%$ and $108.2 \%$, the details of their calculation method and ion suppression data were not described in their paper. Therefore, it is difficult to compare their method with the method presented here.

Application. The validated method was then applied to an analysis of samples from patients with GLUF and GLYP 
poisoning. Patients' serum concentrations of GLUF and GLYP were 487 and $6758 \mu \mathrm{g} / \mathrm{mL}$.

\section{Conclusion}

In conclusion, we described a method for the determination of GLYP and GLUF in human serum. This method needs only a simple centrifuge for sample extraction and can be easily implemented into routine practice compared with previously reported methods. Compared with the previously published GC-MS method, the LC-MS/MS method reduces the analysis time from $20 \mathrm{~min}$ to $7 \mathrm{~min}$, which makes the application of this method to clinical samples possible, in addition to rapid toxicological screening of GLYP and GLUF-poisoning samples. Particularly, this method is suitable for the rapid screening of acute intoxication by GLUF and GLYP, rather than after intensive care treatment.

\section{Compliance with Ethical Standards}

Conflict of Interest. All authors declare that they have no conflict of interest.

Ethical Approval. All procedures performed in studies involving human participants were in accordance with the ethical standards of Tokai University School of Medicine. Informed consent was obtained from all individual participants included in the study.

\section{References}

1. Koyama, K.; Andou, Y.; Saruki, K.; Matsuo, H. Vet. Hum. Toxicol. 1994, 36, 17.

2. Watanabe, T.; Sano, T. Hum. Exp. Toxicol 1998, 17, 35.

3. Tanaka, J.; Yamashita, M.; Yamashita, M.; Matsuo, H.; Yamamoto, T. Vet. Hum. Toxicol 1998, 40, 219.

4. Hirose, Y.; Kobayashi, M.; Koyama, K.; Kohda, Y.; Tanaka, T.; Honda, H.; Hori, Y.; Yoshida, K.; Kikuchi, M. Hum. Exp. Toxicol 1999, 18, 305.

5. Matsukawa, Y.; Hachisuka, H.; Sawada, S.; Horie, T.; Kitammi, Y.; Nishijima, S. Clin. Toxicol 1991, 29, 141.

6. Ohtake, T. Hum. Exp. Toxicol 2001, 20, 429.

7. Motojyuku, M.; Saito, T.; Akieda, K.; Otsuka, H.; Yamamoto, I.; Inokuchi, S. J. Chromatogr. B 2008, 875, 509.

8. Saito, T.; Aoki, H.; Namera, A.; Oikawa, H.; Miyazaki, S.; Nakamoto, A.; Inokuchi, S. Anal. Sci 2011, 27, 999.

9. Saito, T.; Miura, N.; Namera, A.; Oikawa, H.; Miyazaki, S.; Nakamoto, A.; Inokuchi, S. Forensic. Toxicol 2012, 30, 1.

10. Kataoka, H.; Ryu, S.; Sakiyama, N.; Makita, M. J. Chromatogr. A 1996, 726, 253

11. Tsunoda, N. J. Chromatogr. A 1993, 637, 167.

12. Hori, Y.; Fujisawa, M.; Shimada, K.; Hirose, Y. J. Anal. Toxicol 2001, 25,680

13. Hori, Y.; Fujisawa, M.; Shimada, K.; Hirose, Y. J. Anal. Toxicol 2003, $27,162$.

14. Hori, Y.; Fujisawa, M.; Shimada, K.; Sato, M.; Kikuchi, M.; Honda, M.; Hirose, Y. J. Chromatogr. B 2002, 767, 255.

15. Hori, Y.; Fujisawa, M.; Shimada, K.; Sato, M.; Honda, M.; Hirose, Y. J. Chromatogr. B 2002, 776, 191.

16. Sancho, J.V.; López, F.J.; Hernández, F.; Hogendoorn, E.A.; van Zoonen, P. J. Chromatogr. A 1994, 678, 59.

17. Yoshioka, N.; Asano, M.; Kuse, A.; Mitsuhashi, T.; Nagasaki, Y.; Ueno, Y. J. Chromatogr. A 2011, 1218, 3675.

18. http://www.ich.org/fileadmin/Public_Web_Site/ICH_Products/Guidelines/ Quality/Q2 R1/Step4/Q2 R1_Guideline.pdf. Accessed 28 July 2018.

19. http://www.labcompliance.de/documents/FDA/FDA-Others/Laboratory/f507-bioanalytical-4252fnl.pdf. Accessed 2 March 2018. 